\title{
RESENHA
}

\section{Nas brechas do real esfacelado}

Uma escrita impecável, com palavras estudadas, belas imagens quase apolíneas - não obstante, o que mais nos toca no livro Tela atravessada, do jovem André Queiroz, é esta espécie de "dandysmo" discreto, um inegável retraimento da presença que contrasta com suas formulações provocantes. ágeis e coreográficas. Trata-se de um ensaio sobre cinema e filosofia. onde a conviç̧ão transmitida ao corpo das palavras explode, através de diversos filmes, em fotografias do mundo contemporâneo que perdeu suas referências (éticas, políticas e etc.) Esse parece o traço invisível que costura a seleção dos filmes: resistir às armadilhas do "vazio do sentido"; promover na esfera desse vazio a moldura para um outro pensar. um pensar pesado, indo dos simulacros atuais à loucura da corporeidade esgarçada do sem dentro algum da obra de Artaud.

\section{A descorporificação do presente}

André Queiroz não abandona a estratégia dupla comum a muitos livros: ter dois títulos. Assim escreve Tela atravessada (é um livro sobre cinema), mas o subtítulo nos diz que isso ocorre a propósito da relação entre a filosofia e cinema. E tendo em conta a diversidade dos filmes. quais questões filosóficas sustentam a vocação deambulatória dos diferentes ensaios presentes nessa obra? A primeira é com certeza o esfacelamento do real a partir de uma fractalização de valores no mundo contemporâneo. "Pós-orgia", este termo, retomado por André, é uma expressão criada por Jean Baudrillard ao traçar um quadro mais ou menos desolador dos tempos em que vivemos. André caminha junto com Baudrillard para pensar. no limite de todos os desmantelamentos presentes nos dias atuais, um deserto que parece crescer pelas bordas. E com certeza o cinema tem conseguido expressá-lo. A filmografia escolhida permite ao livro Tela atravessada que não se detenha apenas numa constatação perturbada perante os sinais aterradores de niilismo e barbárie que nos são contemporâneos. Procura um fio, ainda tênue, para nos conceber uma arte alegria trágica, mesmo que

\footnotetext{
* Mario Bruno é filósofo, doutor em Teoria Psicanalitica pela UFRJ e Professor do Instituto de Letras da UERJ
} 
suspeitando do vazio de idéias deste nosso virar de século.

Talvez o termo "pós-orgia" não tenha a força de um conceito filosófico, mas serve para nomear uma descorporificação do presente, uma desmaterialização do real. É em torno dessa descorporificação que podemos reunir o cinema de diretores tão diferentes, entre eles Costa-Gravas, Peter Weir, Danny Boyle, Walter Salles Jr. (e Daniella Thomas)?

Poder-se-á suspeitar, quando se fala em "vazio", o que se lamenta é isto: não existem hoje idéias que salvem nem idéias que fundamentem. Com certeza, Baudrillard tem levado esse problema contemporâneo às ultimas consequiências. Desde seus trabalhos iniciais, ele tem associado o fetichismo a um desejo perverso de código que expulsa as contradições pertencentes aos processos reais. Segundo Baudrillard, a mercadoria invade campos novos, distantes do valor específico da troca econômica. A lógica da mercadoria é uma sistemátização progressiva atuando num sistema virtualmente total capaz de substituir todos os valores por valores signos. A fetichização da mercadoria é um trabalho de significação e codificação. Deste modo, esvazia-se a corporeidade do real, tornando-o investido de desejos errantes. Já em textos relativamente recentes, é o caso de $\underline{A}$ transparência do mal (1990), Baudrillard aposta numa visão hiperbólica do sistema de equivalências, no qual o "sistema funciona não tanto pela maisvalia da mercadoria mas pela mais-valia estética do signo" (BAUDRÏLLARD, J. (1990) p.23.), é a era da "pós-orgia", ou do "estádio

154 fractal" de todos os valores:

A lei que nos é importante é a da confusão dos gêneros. Tudo é sexual. Tudo é político. Tudo é estético. [...] - o grau Xérox da cultura. Cada categoria é levada a seu mais alto grau de generalização e, por isso, perde toda a especificidade e se desfaz em todas as outras. Quando tudo é político, nada mais é político, e a palavra já não tem sentido, Quando tudo é sexual, nada mais é sexual, e o sexo perde toda a determinação. Quando tudo é estético, nada mais é belo nem feio, e a própria arte desaparece (Ibidem, p. 15 e 16.).

Era do "pós-orgia" significa a perda de qualquer referência, num grau máximo de generalidade os signos todos se equivalem e circulam soltos, nada os fundamenta. É nesse mundo sem referência que André Queiroz situa a temática de $\mathrm{O}$ quarto poder, filme de Costa-Gravas. Num presente descorporificado refém e seqüestrador se equivalem. A função/ acontecimento (sequiestro) pode ir passando de mão em mão por sua precariedade. E mais: o repórter torna-se o grande seqüestrador porque conhece o caráter auto-referente da imagem.

O Show de Truman, de Peter Weir, torna essa desmaterialização do real mais evidente. Trata-se dos limites de uma cidade-cenário que padece de tempo real. 
Completando esse quadro temos, em Tela atravessada, a interpretação do filme Trainspotting: sem limites de Danny Boyle. O filme apresenta vidas num estilo bordeline (indo da euforia à overdose). É o mundo do pós-orgia onde o tempo, abolido de todo acontecimento, anuncia o fim do político, do sexual, do estético. Diz-nos André: "o vazio e a desesperança típicos do pós-orgia, seriam suficientes para condenar de antemão quaisquer agenciamentos coletivos de desejo" (QUEIRÓZ, A. (2001) p.78).

Resta o mais importante: o que fazer no após a orgia. quando todos os signos se equivalem? Na visão de André, essa é a questão que aparece em Terra estrangeira, de Walter Salles Jr e Daniella Thomas: a fuga de um país de terceiro mundo. que massacra todas as possibilidades de singularização. força o ingresso numa europa xenófoba onde as ofertas subjetivas não chegam a permitir linhas de fuga que ativem no corpo um contorno alegre.

\section{Imagens não-subjetivas, acontecimentos pré-individuais}

Poderá o leitor ser sensível a uma segunda vertente filosófica $€ m$ Tela atravessada. Não é mais o nome de Baudrillard que salta aos olhos e sim o de Gilles Deleuze. O grande mérito consiste em não procurar uma "mensagem" deleuziana, mas um "movimento" que cria a partir das imagens seu próprio campo operatório, resgatando nos filmes a mobilidade vertiginosa de cada um (a fidelidade ai é fundamental, são filmes vertiginosos).

Diretores tão diferentes, Kiarostami, Bergman, Kieslowski, Resnais, o que os aproxima? André parece responder essa pergunta a partir de Gosto de cereja, de Kiarostami, há algo de trágico nesse filme: o apagamento da individuação para a determinação do singular. E a questão se desdobra: assim podemos dizer que Never e Hiroshima, em Hiroshima mon amour, de Resnais, são nomes de singularidades, de estados intensos que ultrapassam os limites individualizados dos corpos das personagens ou das cidades. E o que são esses estados afetivos intensos senão a experimentação do "outro" que quebra a "ideologia da segurança material". $E$ isso nos remete ao problema central do filme de Bergman, Cenas de um casamento: a singularização "deve ser catalizadora de práticas de 'outramentos' que nos desestabilize de nossas certezas, que nos diferencie r'o que nós somos, e que nos desautorize de nós mesmos" (ibidem, p.87).

É claro que Tela atravessada rão se deixa inserir numa quadrícula apertadí de explicitação uma teoría da diferença no mundo contemporâneo através do cinema. Há neste livro uma tentativa de manter a distância justa encre $a$ teoria a as imagens.

Seguindo uma fundamentação deleuziana, o autor de Tela atravessada percorre através de uma filmografia bem selecionada, o universo dos confrontos entre a asfixia sem linhas de fuga do mundo atual e o campo 
processual dos afetos com seus riscos desterritorializantes. Com isso vemos a "estrangeiridade" da trilogia de Kieslowski (Trois Couleurs) que chama a todo instante por planos de consistência, mas também vemos $\underline{\mathrm{Na}}$ companhia dos homens, de Labute, com seus vetores de microfacismos achatando singularizações pré-individuais, num universo underground feito de trapaças. Uma face bem próxima disso André encontra, também, no filme Ódion, de Kassovitz, através do problema dos skinheads e do medo crescente de terceiro mundialização dos países desenvolvidos.

\section{O acáso singular sobre si mesmo}

A terceira influência em Tela atravessada é de Carlos Henrique Escobar. $\mathrm{Na}$ verdade trata-se de um "anexo". Neste ponto assumo uma primeira pessoa do singular para uma confissão: leio Escobar com certo temor. Medo de entrar numa matéria espessa, desgrenhada, grumosa, em que me perco e me escapa. Mas o artigo "Nietzsche/Artaud e o lugar do pensamentooutro"nos vem em auxílio, ajuda a tornar as coisas um pouco mais claras, dando uma gravidade extrema às questões. A referência é a Cena Nietzsche atravessando a loucura sem interioridade de Van Gogh e Artaud. O que se convencionou chamar de Razão entra em confronto com a radical abismalidade de um "pensar pesado do pensamento" que pensa a partir do "acaso singular sobre si mesmo". Este artigo evoca a porção de loucura na fragilidade dos olhares e a exterioridade mesma do "além homem". O que está em questão é o trágico da dor, da loucura e da morte (nessa errança da cena/corpo de Nietzsche a sussurrar o pensamento do eterno retorno). Salta-nos aos olhos a solidão Nietzsche/Zaratustra experimentada onde ela se mostra mais espessa..E nesse "pensar pesado" os conceitos se avolumam, seja na cena de uma crueldade, seja na "corporeidade suja" do "pensamento-corpo". Embora não concordemos com a idéia de "destragicização" que Escobar vê em Deleuze, destacamos a beleza da plasticidade do texto de André que enquanto pensador da diferença nos apresenta esse Outro: espécie de pensamento corporalizado em que "o Eu se decompõe numa lucidez maior e mais breve" (KLOSSOWSKI, P. (2000) p.51). 


\section{NORMAS PARA PUBLICAÇÃO}

\section{Submissão de artigos}

Contracampo acolhe colaborações de autores do Brasil e do exterior, pertencentes ou não a programas de Comunicação. Os trabalhos submetidos são avaliados por dois pareceristas do Conselho Editorial e publicados após recomendação de ambos, obedecendo às datas de fechamento dos números semestrais.

SOMENTE ARTIGOS INÉDITOS PODERÃO SER SUBMETIDOS A CONTRACAMPO.

\section{Formato e preparação de artigos para submissão}

Os trabalhos submetidos devem possuir entre 5000 a 7000 palavras, ou de 13 a 15 laudas, digitadas em Word (ou similar), fonte Times New Roman, corpo 12.

O formato da página adotado para os trabalhos é o A4 $(21 \times 29.7 \mathrm{~cm}) \mathrm{com}$ as seguintes medidas: $2 \mathrm{~cm}$ de margem superior; $3 \mathrm{~cm}$ de margem inferior, $5 \mathrm{~cm}$ de margem esquerda, $3 \mathrm{~cm}$ de margem direita e medianiz 0 . Cabeçalho de 1.2 $\mathrm{cm}$ e rodapé de $1,6 \mathrm{~cm}$. Alinhamento pela esquerda somente.

O espaço entre linhas deve ser simples para o corpo do texto, e o espacejamento do parágrafo deve ser de 12 antes e 6 pontos depois de cada parágrafo, com recuo direito e esquerdo de valor 0 .

Todos os parágrafos devem ser indentados em $0.5 \mathrm{~cm}$.

\section{Título e autoria}

Fonte Arial, negrito, corpo 12, centrado e espacejamento entre linhas de 1,5 linhas. Usar caixa-alta (letra maiúscula) apenas para a primeira letra do título do artigo. exceto para nomes próprios ou palavras que exijam o uso de caixa-alta por razöes gramaticais.

O nome do autor deve ser colocado abaixo da última linha do título, centrado. em Arial, itálico, corpo 10. Se o artigo possuir mais de um autor, separar os nomes destes com um vírgula e espaço. Se o número de autores exceder uma linha, não dividir o nome de um autor: coloque-o na linha seguinte. O nome de cada autor deve estar na seguinte ordem: primeiro nome, segundo nome ou inicial (se for o caso) e o sobrenome.

Incluir no final da primeira página do artigo nota de rodapé (com entrada após o sobrenome de cada autor, numeração personalizada por asterisco) com dados biográficos sobre $\mathrm{o}(\mathrm{s})$ autor(es), constante de filiação institucional, titulação, etc. com cerca de 50 palavras. em fonte A rial, regular, corpo 9. 


\section{Palavrás-chave e resumos}

As palavras-chaves e resumo em português devem vir após o título e nome dos autores.

Usar 3 a 5 palavras-chaves, fonte Arial, corpo 10. Estas devem ser colocadas antes do resumo e serem antecedidas da palavra: "Palavraschaves"; alinhada à esquerda, em Arial, negrito, corpo 10.

O resumo deve ter aproximadamente 150 palavras. Usar fonte Arial, corpo 10 para o resumo. As especificações para parágrafo e coluna são as mesmas do corpo do texto (siga as instruções dadas para margens, espacejamento, indentação, coluna e alinhamento). O resumo deve ter como título a palavra "Resumo", a linhada à esquerda, em Arial negrito, corpo 10. $\mathrm{Na}$ linha seguinte coloque o texto do resumo.

As palavras-chaves e resumo em inglês devem observar o mesmo formato para o português, sendo, porém, em itálico. Devem vir após o resumo em português. Substituir os títulos: "Palavras-chaves" por "Keywords" e "Resumo" por "Abstract", pára as palavras-chaves e resumo em inglês.

O texto do artigo deve ser iniciado na página seguinte às palavraschaves (keywords) e ao resumo (abstract) em inglês. Para tanto, inserir quebra de página entre a página com título, autoria, resumo e abstract e corpo do artigo.

158 Não inserir numeração nas páginas.

\section{Subtitulos}

Sugerimos o uso de não mais de três níveis de subtítulos para seu artigo, os quais devem seguir estas especificações:

- primeiro nível de subtítulo: Arial, negrito, corpo 11, alinhado à esquerda; espaço de parágrafo de 24 pontos antes do subtítulo e de 6 pontos após o subtítulo;

- segundo nível de subtítulo: Arial, negrito, corpo 10, indentado em $0.5 \mathrm{~cm}$, espaço de parágrafo de 12 pontos antes do subtítulo e de 6 pontos após o subtítulo;

- terceiro nível de subtítulo: Arial, negrito, itálico, corpo 10, indentado em 1.Sem, espaço de parágrafo de 12 pontos antes do subtítulo e de 6 pontos após o subtítulo.

Usar caixa-alta (letra maiúscula) apenas para a primeira letra do subtítulo do artigo, exceto para nomes próprios ou palavras que exijam o uso de caixa-alta por razões gramaticais.

Inserir um parágrafo (Enter) entre o texto que antecede o subtítulo e este. 


\section{Imagens}

Para o envio de material fotográfico. os editores devem ser previamente contatados para maiores especificações.

\section{Citações}

Para citar um autor no corpo do texto use 'aspas simples". Citaçōes que excedam três linhas devem ser separadas do corpo do texto (aperte a tecla 'enter' uma vez).

Para citações, usar fonte Arial, regular, corpo 9, alinhamento à esquerda. Espacejamento entre linhas deve ser simples, recuo de parágrato de $0.5 \mathrm{~cm}$, e espaço de 6 pontos após cadil parágrafo de sua citação (se for o caso).

\section{Notas}

Usar notas de final de documento apenas. com exceção da nota biográfica do(s) autor, que aparece na primeira página do artigo. Usar fonte Arial, regular, corpo 9; e alinhar o texto pela esquerda. Usar notas de rodapé quando absolutamente necessário e evitar notas longas. As notas devem ser numeradas consecutivamente ao longo do texto.

\section{Referências}

As referências bibliográficas devem vir logo após a seção de notas e seguir a NBR 6023 DA ABNT observado o formato de margens e espaços definidos acima. Todas as referências devem vir listadas alfabeticamente $\mathrm{c}$ cronologicamente na seção de referências. sob o título "Referências" (ver especificações para títulos de primeiro nível). Para formatar as referências use fonte Times New Roman, regular, corpo 12, alinhamento à esquerda. espacejamento simples entre linhas, recuo especial de $0.5 \mathrm{~cm}$ da segunda linha em diante e espaço de parígrafo de 6 pontos após cada referência.

\section{Considerações sobre direitos autorais}

Os artigos submetidos devem vir acompanhados de autorização de publicação pelo autor.

Contracampo detém o copyright sobre o conteúdo da publicação aceita.

Fotocópias de artigos são autorizadas mediante solicitação ans editores e crédito das fontes.

Para evitar violaçäu, das leis de direitos autorais, favor não utilizar longas e muitas citaçós de uma mesma fonte, ou figuras publicadas previamente sem um documento de autorização de uso dos direitos autorais. Isto também se refere a imagens produzidas pelo autor, publicadas 
em outro veículo, cujo direito autoral tenha sido transferido à editora referente ao veículo anterior. Autores que não fornecerem documentos de autorização de uso de direitos autorais terão seus artigos devolvidos.

\section{Envio de artigos:}

Os originais deverão ser enviados em três cópias impressaș, acompanhadas de disquete, para o seguinte endereço:

Rua Tiradentes, 148, Ingá/ Niterói - CEP: 24270-240

Rio de Janeiro- $\mathrm{RJ}$

Contracampo

Uma revista financiada pelo programa PROAP/CAPES.

e-mail para contato: sibonei@gbl.com.br 


\section{2}


IMPRESSÃO E ACABAMENTO:

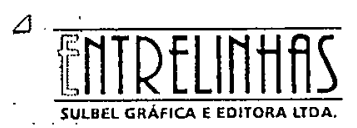

ENTRELINHAS SULBEL GRAFICA E EDITORA LTDA.

Rua Dr. Catrambi, 240 - Alto da Boavista - CEP 20531.005 - Rio de Janeiro - RJ

Tel./Fax.: (21) 2571-8072 - Tels (21) 3905-7959-2278-4908

e-mail:entrelinhassulbei@hotmail.com

500 Exemplares 
De como Antonio Banderas perdeu o sotaque - e outros fenômenos transnacionais

Emma e As Patricinhas de Beverly Hills: Relações Irônicas

Espectatorialidade no diálogo cine/TV

Política da Representação

Programas de desemprego programado

A construção de uma história do cinema brasileiro: política estatal e cinema alternativo nos anos Embrafilme

\section{ARTIGOS}

A proteção à infância na televisão européia

A TV, os Literatos e as Massas no Brasil

\section{ENTREVISTA}

Ismail Xavier: o cinema e os filmes ou doze temas em torno da imagem

\section{RESENHA}

Nas brechas do real esfacelado

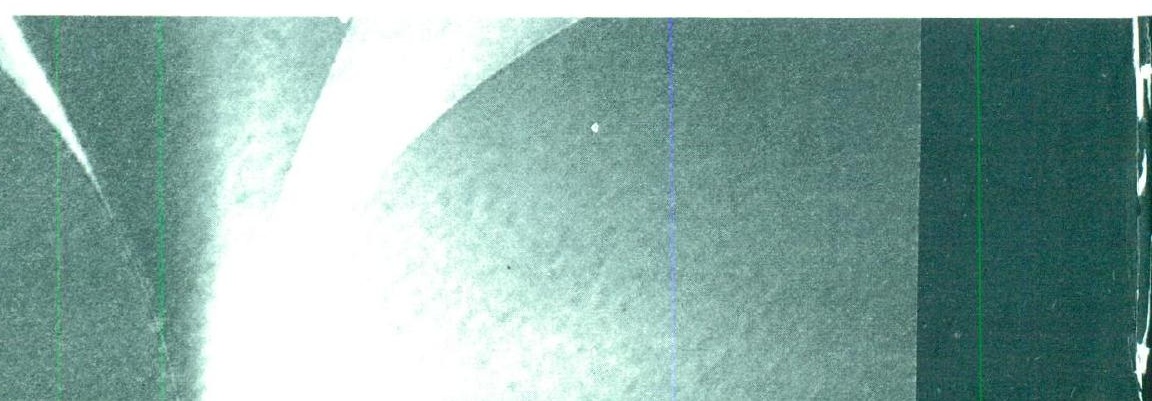

